Supporting Information

\title{
Synthesis and magnetic properties of uniform hematite nanocubes
}

Shang-Bing Wang, Yu-Lin Min, Shu-Hong Yu*
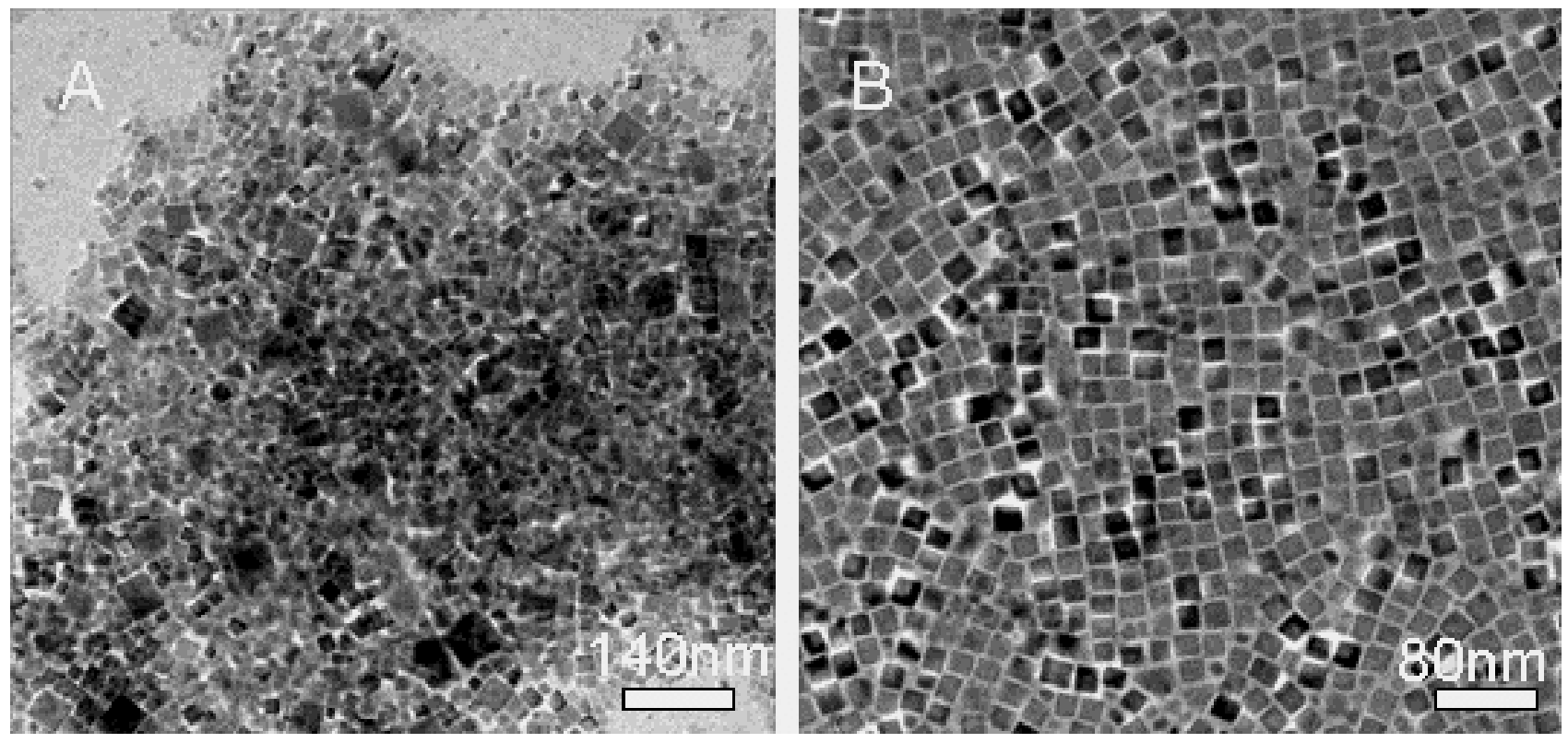

Figure S1. TEM images of the samples obtained in a typical synthesis. (A) the as-synthesized product, and (B) after a size-selective process. 


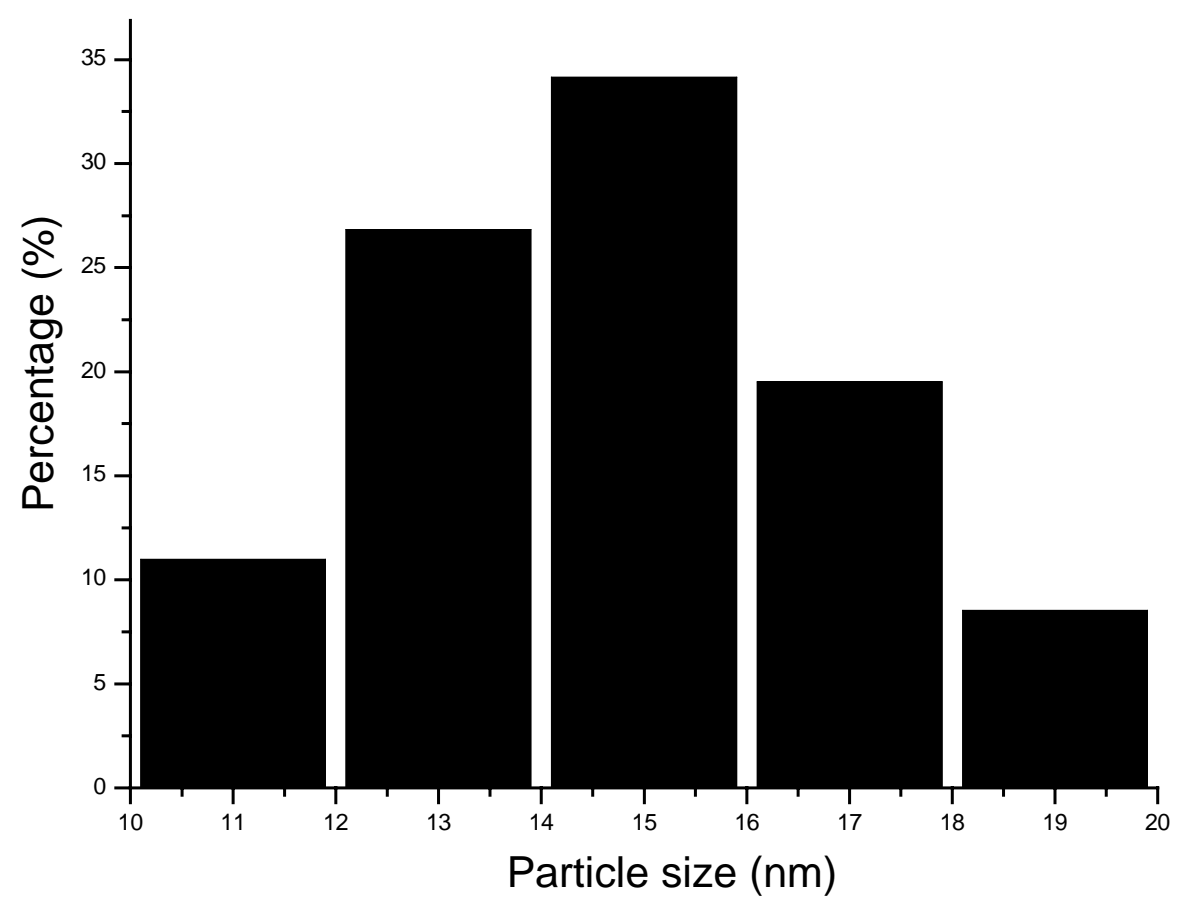

Figure S2. The size distribution of hematite nanocubes based on counting 164 nanocubes.
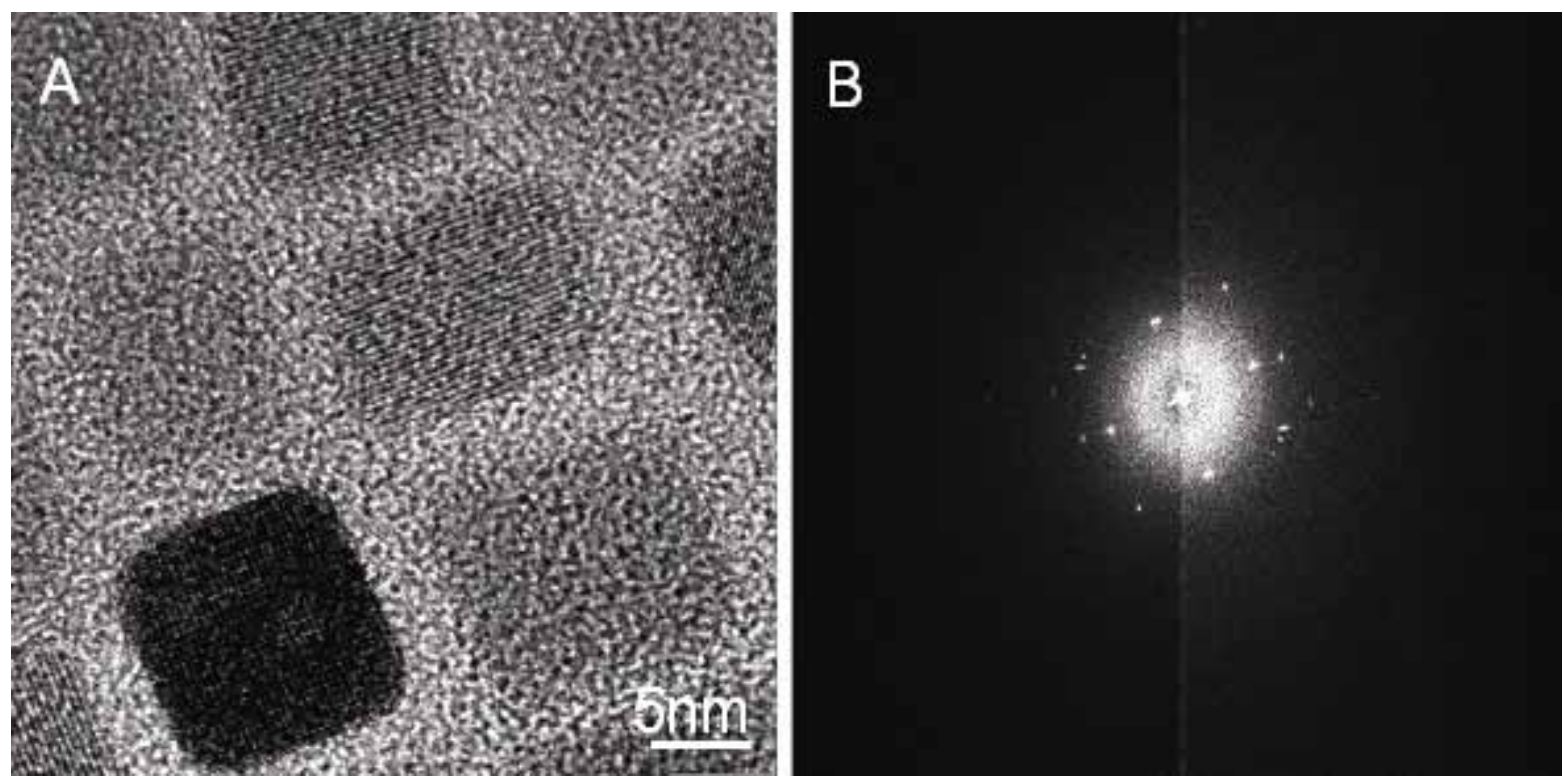

Figure S3. High resolution TEM image of hematite nanocubes (A), and the corresponding FFT pattern of this area (B). 

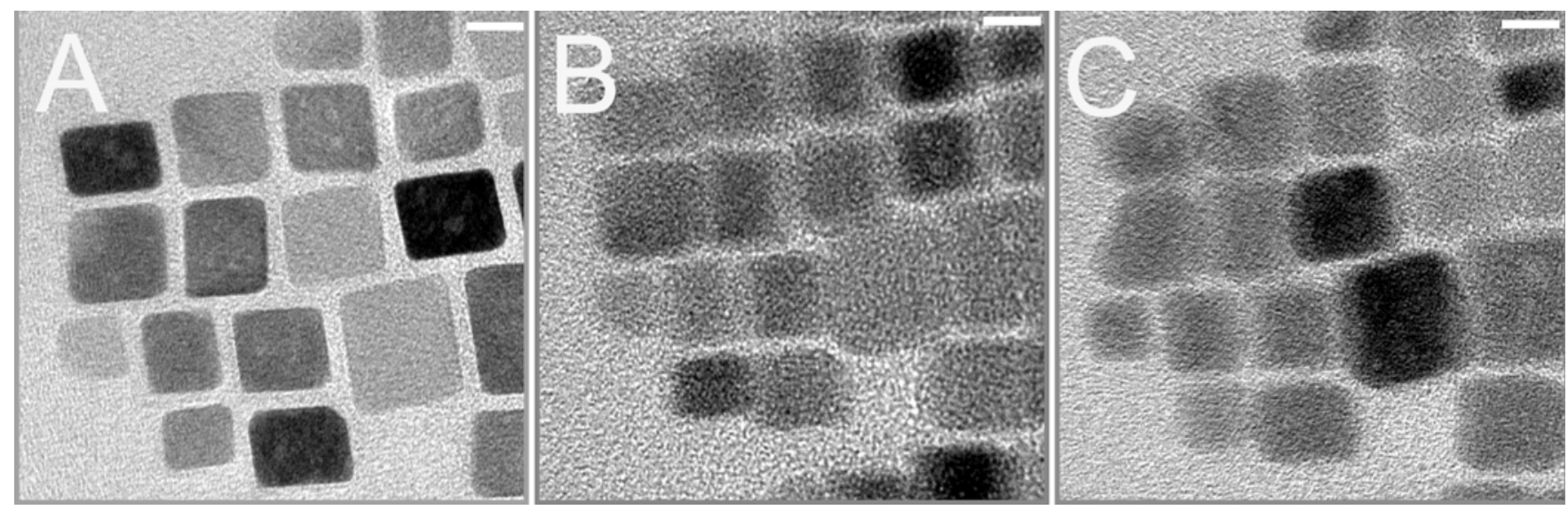

Figure S4. TEM images of hematite nanocubes by tilting along the y-axis of TEM, showing that the nanocrystals are truly cube-shaped. From A to C, Tilted TEM images obtained at $0^{\circ}, 30^{\circ},-30^{\circ}$, respectively, while fixed along the $\mathrm{x}$-axis. Bar, $10 \mathrm{~nm}$.

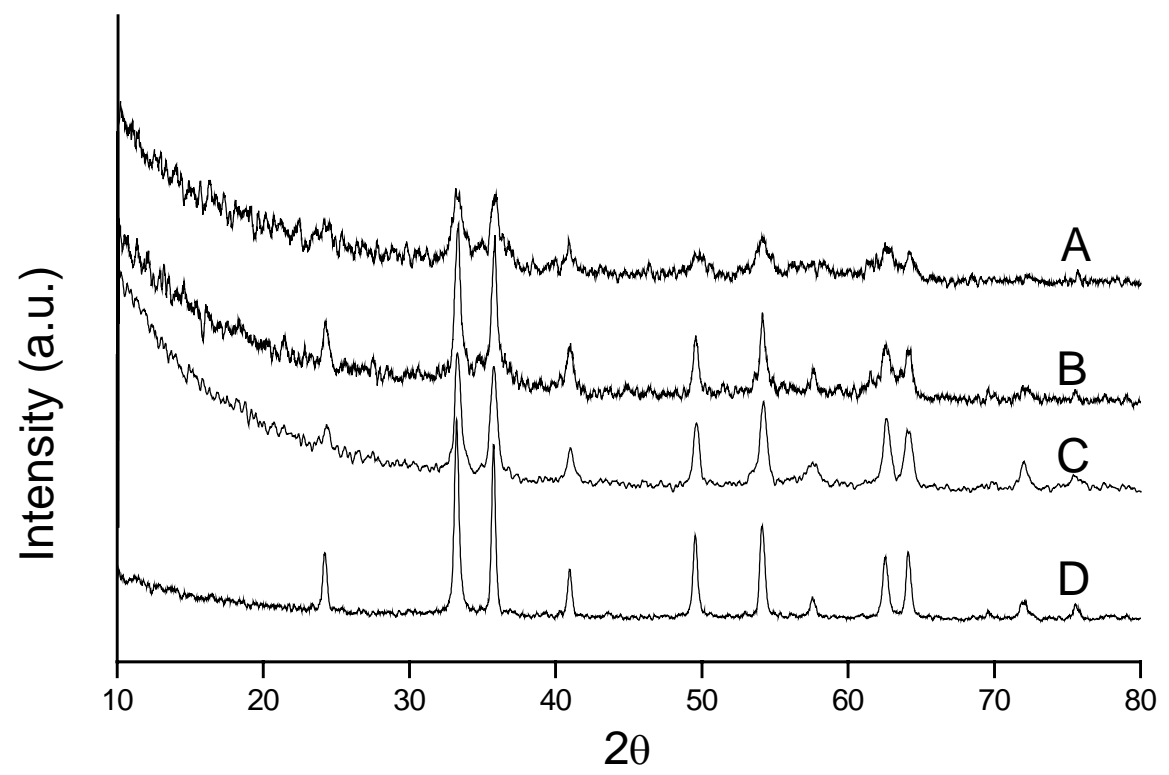

Figure S5. XRD patterns of the as-synthesized products from different temperatures. A, B, C, and D corresponded to $120{ }^{\circ} \mathrm{C}, 140{ }^{\circ} \mathrm{C}, 160{ }^{\circ} \mathrm{C}, 180{ }^{\circ} \mathrm{C}$, respectively. 


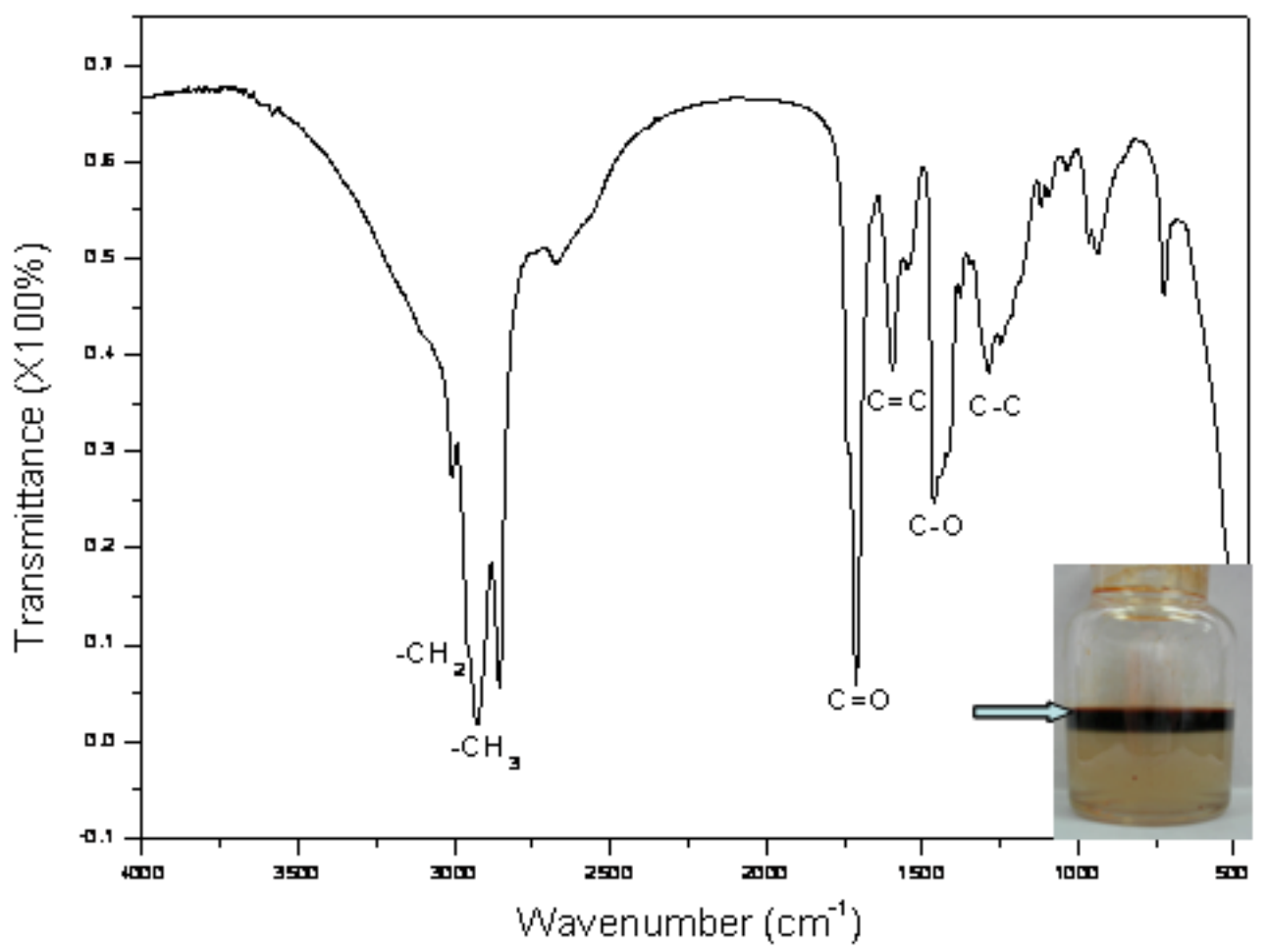

Figure S6. FT-IR spectrum of the iron-oleate complex. The sample from the upper henna organic layer of the reaction system (inset) after treated at $80{ }^{\circ} \mathrm{C}$ for $5 \mathrm{~h}$.

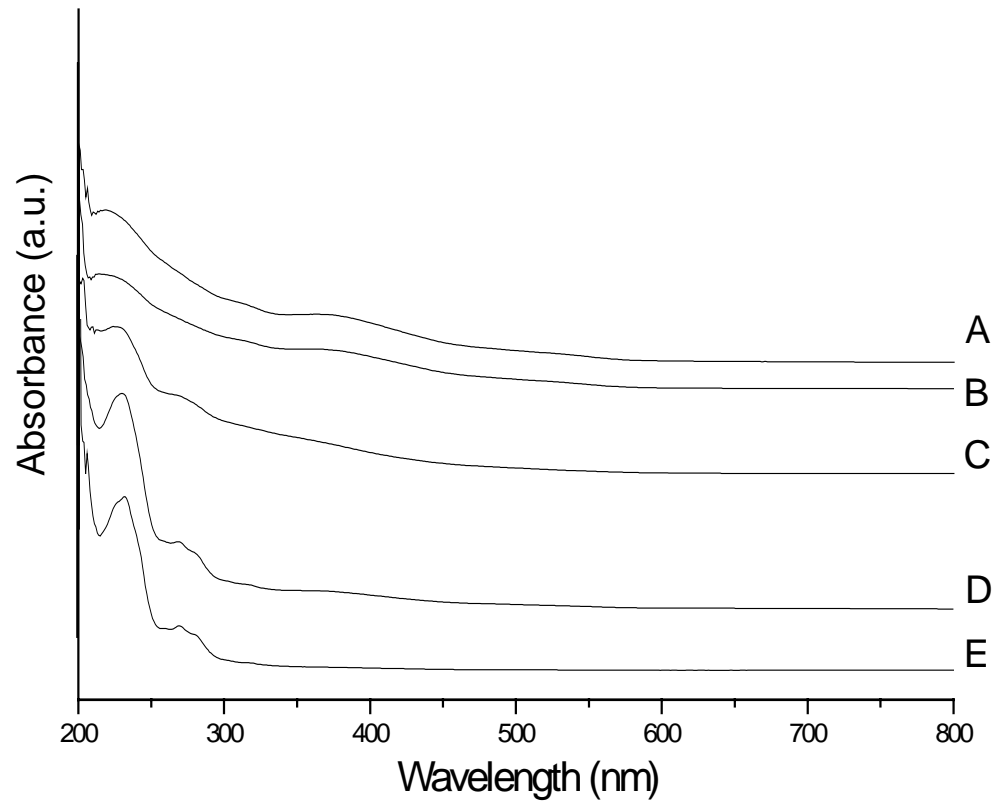

Figure S7. UV-Vis spectra of cyclohexane-dispersed hematite nanoparticles colloidal solution. Curve (A) was from the sample obtained with a molar ratio of sodium oleate: $\mathrm{FeCl}_{3}=3.5$ :1; Curves (B), (C), (D), and (E) from the samples obtained at $120^{\circ} \mathrm{C}, 140^{\circ} \mathrm{C}, 160^{\circ} \mathrm{C}, 180^{\circ} \mathrm{C}$, respectively. 